\title{
Managing the Risks of Power System Balancing Considering f-P Control as a Service of the Balancing Market and the Influence of Renewable Energy Sources
}

\author{
Omer HADŽIĆ* Z Zijad BAJRAMOVIĆ, Sejid TEŠNJAK
}

\begin{abstract}
The safety of managing the electric power system (EPS) in free, deregulated electricity market solves the problem of techno-economic risks related to operative balancing of the system by taking into consideration one of the ancillary services, that is frequency control and exchange active power ( $f-P)$, and contribution of renewable energy sources in a specific surrounding. It is well known that the electricity market derives significant risks for all participants, especially for the transmission system operator (TSO) which is responsible for balancing electricity generation and consumption regardless of their probability, which means they have stochastic nature. Therefore, the main idea is to provide the safety of the system's drive by analysing certain risks related to the problem of balancing the process of electricity generation with the goal: "maximum safety and minimum risk". The power trading and ancillary services provision comprise technical and financial risks and therefore require a structured risk management. Focus of this paper is on financial risk management that is important for the system operator faces when providing and using ancillary services for balancing of power system.
\end{abstract}

Keywords: ancillary services; electricity balancing; electric power system; $f-P$ control; renewable energy; risk management

\section{INTRODUCTION}

The aim of this paper is directed towards a solution proposed for one of the problems related to increasing the safety of the managing process of the EPS (electric power system) in free electricity market conditions. Essentially, this is a research of techno-economic risks of electricity balancing of the EPS by using $(f-P)$ control as an ancillary service which is related to the electricity market and by taking into consideration contributions of renewable energy sources as well. It is necessary to optimize the important risks of the balancing with the purpose to ensure the greatest safety (global) of the EPS and the lowest risk [1].

In terms of the main components of risk in the market operations the following is taken into account [2]:

- the basic market and the ancillary services market,

- unstable prices of electricity,

- procurement of electricity for the balancing,

- $\quad$ safe control of the EPS in real time which is a basic

assumption for secure supply of electricity consumers.

The transmission system operator in any country of the world is exposed to the risk of safe control and consumers supply. Such risk essentially as well as theoretically may be divided in two parts: the operational and the financial one [1].

Operational risk: the transmission system operator is exposed to the concerned risk. The risk may be reduced by introducing a national or an international ancillary services market.

Financial risk: this risk is shared with all other subjects responsible for energy deviations.

Deregulation of the electricity market increased transparency in trading and enabled implementation of financial instruments in such market [3]. Besides the balancing of electricity supply and demand, the electricity market provides suppliers and users with various methods to 'protect' themselves from high volatility of electricity prices. Forward contracts i.e. future contracts have an important role in the allocation process in the system managing risks, and are related to market prices and to premiums which are correspondent to a risk of so called spot and forward prices [4].
This ideal possibility of electricity market does not exist due to the market's imperfection in terms of the lack of consumption, relatively inadequate manageability of the local market and so called political resistance to relatively high prices which all result in reduced electricity consumption in the EPS.

The paper is structured in the following way. In the second section description of the ancillary services in the EPS is given. In the third chapter theoretical background is given. Risk premium and price modelling is given in chapter four. Overview of the elements of planning, procurement and of the contracting process of individual service with comparison of unit prices in the EU member countries is given in the fifth chapter. Finally, conclusion is given in section six.

\section{DESCRIPTION OF THE SYSTEM}

It is the task of any TSO in the world as well as of a responsible regulatory body to make the most successful prediction and assessment of possible risks in a deregulated market and to choose the most appropriate methods which are important for successful risks managing and which enable safe operation and management of the EPS in accordance with the safety requirements of final users.

Managing the most of possible risks to which the TSO (Transmission System Operator) is 'exposed' in the electricity market is a multisized/multidisciplinary process.

In practice there is a need to identify realistically possible and relevant risks in a deregulated electricity market in terms of the balancing problem, including ancillary services in the EPS along with a share i.e. a role of renewable energy sources [5]. The balancing problem is related to the deviations of the exchange power associated with the imbalance in the control areas of the observed EPS. Activation of $f-P$ regulation activates the market parameters coming from the activation of the $f-P$ regulation of all control areas in the connected EPS. Therefore, the goal of each control area is to minimize the error of the control area in real time:

$G=P_{\text {meas }}-P_{\text {prog }}+K\left(f_{\text {meas }}-f_{0}\right)$ 
where $P_{\text {meas }}$ is the sum of the current measured power (MW) at the connecting lines, $P_{\text {prog }}$ is the agreed interchange power with adjacent control areas, $K$ is the control area factor (a constant $\mathrm{MW} / \mathrm{Hz})$, and $\left(f_{\text {meas }}-f_{0}\right)$ represents the difference between the current measured system frequency and the frequency set point.

Having in mind the market risks of the EPS balancing, the managing remains important, but the most important are appropriate algorithms for dealing with the concerned risks.

By now, regulatory changes in electricity markets in the world mostly "transposed" their investment risks from consumers to producers. In so called "ideal" case shareholders of generation companies bear all investment risk and consumers bear so called price risk, while new market participants suppress a possibility of producing electricity according to the market's balance of the system. With such approach to the market, suppliers and consumers are free to choose a level of their risk exposure.

When dealing with risks related to the problem balancing of the EPS with the European market model, it was predicted the establishment of so called European platform for the imbalance netting, secondary (aFRR automatic Frequency Restoration Reserve), direct tertiary (mFRR - manual Frequency Restoration Reserve) and possibly replacement reserve ( $R R$ - Replacement Reserve). Basically it is important that in the balancing system there is a possibility to configure different parameters which define a design of the balancing market. Those parameters relate to: deadlines/scales for certain activities (Gate Closure Times), definition of a method for creating prices - "cap prices", characteristics in the balancing market and similarly. Most of the given parameters are yet to be harmonized on the interconnection level of ENTSO-E (European Network of Transmission System OperatorsElectricity) in the form of an adequate agreement to be made between the European transmission system operators.

Ancillary services in the EPS in any country of the world are important for overall security and reliability of the system. Their importance is contained within the process of supporting the basic functions of the system active power generation, electricity supply, and they are provided by subjects responsible for generation, transmission, distribution and control (control + regulation) of the system. An important characteristic of ancillary services in the EPS is that in any moment it is important to ensure their availability in terms of their capacity/quantity. Therefore the costs of ancillary services are defined as opportunity-costs, or as costs of undelivered active power in the EPS in an amount in which specific ancillary service is to be ensured.

In terms of providing ancillary service in the EPS of any country of the world, the most significant question is that of the cost of a specific service provision. To be more precise, there is an analysis of each ancillary service in the European Union countries (ENTSO-E) in terms of relevant grid codes.

The concerned analysis will take into consideration the following ancillary services [2]:

- black start,

- characteristics of frequency and active power control (primary, secondary, tertiary control),
- $\quad$ voltage control (Q-U control),

- island regime/operation of power plants/systems,

- unloading of the EPS,

- redispatching of the EPS,

restoration of the EPS.

It is very important to determine costs for each of the ancillary services since today for most of them (in literature) there are no adequate and available i.e. reliable data. In addition, it is important, in techno-economic and legal terms, to explore the issue of ensuring ancillary services in the market surrounding such as:

- liability to provide ancillary services,

- providing ancillary services on the basis of a concluded agreement (for example by a periodical tender announcement),

- procurement of ancillary services in the market, for example through the initial bid market of ancillary system services (initial bid market - market with set initial price).

\section{RISK MANAGEMENT}

\subsection{Risk Management Description}

An explanation of the term "risk management" in general starts from standard ISO 31000:2009. The fundamental questions here are [6]:

- Why is there a problem of managing risks?

- Why is it necessary and essential to manage risks?

Fig. 1 shows a detailed structured scheme of risk management components.

Researches indicate that the purpose of risk management is to bring unacceptable risks to an acceptable level and keep them on that level. The point of improvement in terms of risk management is in periodical reducing of "risk appetite". This deals with quantity and types of risks an entity (organization/company) is ready to undertake. However, there are also negative effects of risk management.

It seems important to take into consideration the following parameters:

- increase safety of the system researched,

- the safety of funds usage for the purpose of the implementation of a project safety,

- significant/important possibilities for solving a problem with unexpected damages (undetermined risks),

- participants' discontent with the problem of "safety"; therefore: minimum risk - maximum safety, the objective function.

\subsection{Financial Instruments for Risk Management in the Electricity Market}

Having in mind the problem of implementation of financial algorithms in the electricity market, here it is referred to $[2,7,8]$ :

- forward contracts (Forwards), future contracts (Futures), replacement contracts (Swap), options (Over The Counter - OTC), contracts for difference. 


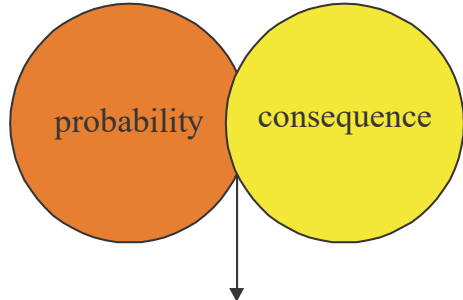

risk $=$ probability $\&$ consequence

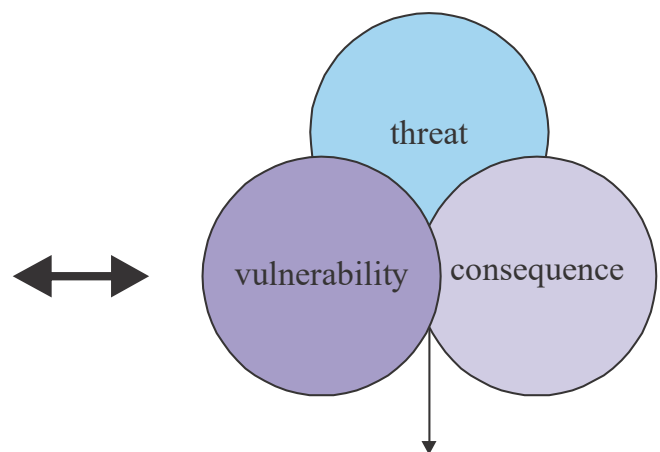

risk $=$ threat $\&$ vulnerability $\&$ consequence

\section{functional relationship}

risk $=$ probability $\times$ consequence

risk $=$ threat $\times$ vulnerability $\times$ consequence

mathematical relationship

Figure 1 Ratio of risk and elements leading to risk (ISO 31000:2009)

\section{RISK PREMIUMS AND PRICE MODELLING \\ 4.1 Risk Premium}

On the basis of [9-11] and in relation to the term 'risk', it was determined that a risk premium depended on numerous factors with the most important being: demand, variation and volatility of prices, spot prices, current prices and seasons' effects.

Generally speaking, risk premium may be ex-ante and ex-post with an important difference that ex-ante risk premium cannot be observed or analysed through the market data, but it depends on a model of determining spot prices. Therefore, ex-post risk premium is determined on the basis of data available in the market and it does not depend on a model chosen for the relevant analysis [12].

Premiums are defined by using the following expressions:

- ex-ante premium:

$$
R(t, T)=F(t, T)-E[S(T)]
$$

- ex-post premium:

$$
r(t, T)=F(t, T)-S(T)
$$

where $S(t)$ is the spot price of an asset at time $t$ and $F(t, T)$ is the forward price observed at time $t$ for delivery at time $T \geq t$. Then the ex-ante risk premium at time $\mathrm{t}$ is $F(t, T)-$ $E(S(T))$, where $E(\bullet)$ is the expectation under the physical probability measure conditional on the $\sigma$-algebra containing the information available at time $t$. The ex-post risk premium at time $t$ is then given by $F(t, T)-S(T)$. The main difference between these two risk premia is that the ex-ante risk premium is not directly observable from market data but is always dependent on the spot price model chosen, whereas the ex-post risk premium is completely observable from market data.

Based on given definitions, it is apparent that the difference between ex-ante risk premium of forward price $F(t, T)$ and expectations for spot price $E[S(T)]$ may be analysed after an expected spot price is modelled, and for that reason it cannot be directly observed on the basis of the market data. It is known that ex-post risk premium is independent of the models, but it can be 'observed' only upon the expiry of forward contracts. However, ex-ante premium is a subject of researches and it is necessary to define this premium as to enable its independence of a model; in this way the researches could be compared. Basically, an alternative approach to this issue [13] is to make assumption of ex-ante premium by using already known and determined ex-post premium. This definition of the premium is related to the contracts being delivered in exactly determined time. Trading processes in the electricity market are occurring for many times and this is performed through so called swap contracts which do not have precisely defined delivery time, but the delivery is done within a specific deadline as defined by a contract. Due to this type of contract, a definition and consequently mathematical formulation of risk premium is being changed [14]. Therefore, in altered version of the delivery time is $\left[T_{1}, T_{2}\right]$, i.e. $0 \leq T_{1} \leq T_{2}<T$, and ex-ante premium is defined by the expression:

$$
R\left(t, T_{1}, T_{2}\right)=F\left(t, T_{1}, T_{2}\right)-E\left[\frac{1}{T_{1}-T_{2}} \int_{T_{1}}^{T_{2}} S(T) d T\right]
$$

However, ex-post premium is mathematically defined as [15]:

$$
r\left(t, T_{1}, T_{2}\right)=F\left(t, T_{1}, T_{2}\right)-\frac{1}{T_{1}-T_{2}} \int_{T_{1}}^{T_{2}} S(T) d T
$$

Eqs. (4) and (5) represent the ex-ante and ex-post risk premium at time $t$.

The practice shows that the risk premium may have positive or negative sign [16]. Risk premium has a positive value in short-end curve of forward prices, i.e. it is closer to the beginning time of electricity delivery. On the other hand, with the delivery time being later, the risk premium is getting a negative sign, hence the producers try to "defend" themselves against a possible risk for not taken 
energy and in that case they sell their forward contracts below the expected spot price.

Ex-post premium risk calculation has been done on the ancillary services for the EPS of Bosnia and Herzegovina. Seven day period was analysed. Hourly prices of each ancillary service for analysed period are given in Fig. 2.

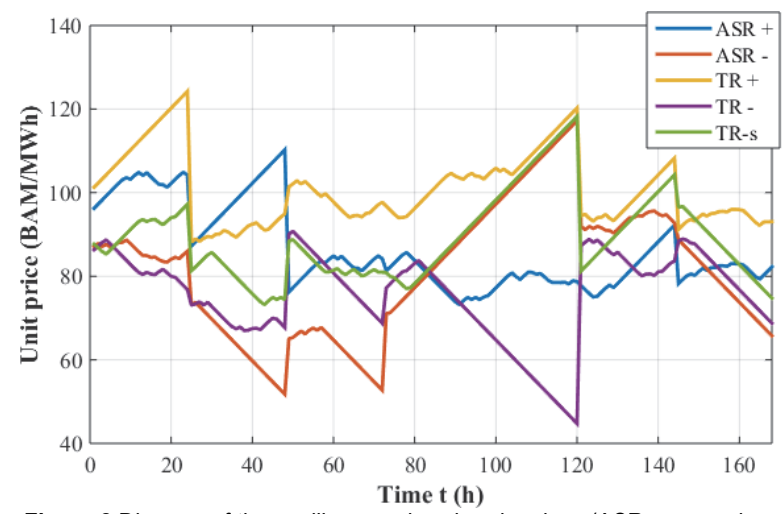

Figure 2 Diagram of the ancillary services hourly prices (ASR + secondary control energy "up", ASR - secondary control energy "down", TR + tertiary control energy "up", TR - tertiary control energy "down"; TR-s energy to secure the system's safety) [15]

For the analysed period, calculated risk premiums for each ancillary service are given in Tab. 1.

Table 1 Risk premium calculation results

\begin{tabular}{|c|c|}
\hline Ancillary service & Risk premium / BAM \\
\hline $\mathrm{AS}+$ & $11.044,82$ \\
\hline $\mathrm{AS}-$ & $10.129,80$ \\
\hline $\mathrm{TR}+$ & $19.789,20$ \\
\hline $\mathrm{TR}-$ & $6.575,74$ \\
\hline $\mathrm{TR}-\mathrm{s}$ & $1.365,97$ \\
\hline
\end{tabular}

Risk management in the electricity market is a term related to business activities of any company. Risk management signifies a system process of estimation, identification, evaluation and calculation of risk and risk activities with the purpose of reducing the probability of risk occurring which can have negative effect on the company's business and its goals. The process of risk management should be well organized (Fig. 3) with clearly defined goals of each singular procedure serving to reduce a probability for risk occurring.

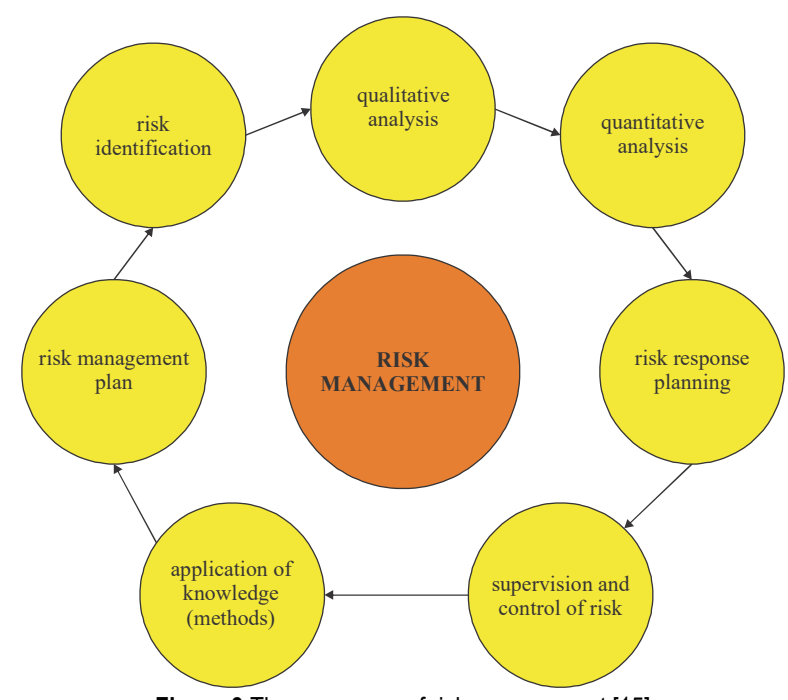

Figure 3 The processes of risk management [15]
The process of risk management should be well organized (Fig. 3) with clearly defined goals of each singular procedure serving to reduce a probability for risk occurring.

In addition to this process of risk management, in practice a method Divide et impera (Fig. 4) is also applied. According to this method there is an attempt to reduce an identified risk and to share it between few participants so they could "more easily" accept eventual losses.

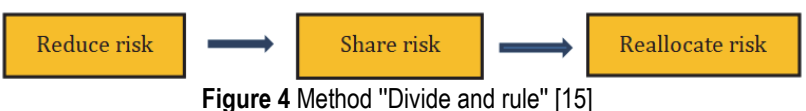

\subsection{Methodology for Determining the Unit Prices of Balancing Services}

Having in mind the problem of the methodology for determining the unit prices of balancing services, an approach was first taken of determining unit prices for providing balancing services (imbalance) in a settlement period for an increase i.e. a reduce of electricity generation within the activation of reserve power for automated frequency restoration reserve and exchange power, activation of reserve power for tertiary control for the system's balancing and activation of reserve power for tertiary control in view of the system's safety.

\subsection{Price in a Monthly Imbalance Settlement}

The problem of defining prices i.e. average prices in given settlement periods and predefined imbalance [EUR/MWh], is defined by adequate mathematical expressions containing:

- electricity balancing costs,

- tolerance limits in a balancing group's settlement interval,

- $\quad$ unit prices for imbalance settlement.

Mathematical models of the mentioned problems are presented and explained in detail in [15]. In addition in [15] there is a detailed description of the system and the balancing model in EPS in Bosnia and Herzegovina in view of unit prices of ancillary services.

\section{ELEMENTS OF PLANNING, PROCUREMENT AND OF THE CONTRACTING PROCESS OF INDIVIDUAL SERVICE WITH COMPARISON OF UNIT PRICES IN THE EU MEMBER COUNTRIES (ENTSO-E) - OVERVIEW \\ 5.1 Ancillary Services Used by the Concerned Transmission System Operators}

The basis of the research is the fact that ancillary services are differently defined across various systems and countries in terms of their definitions and characteristics of each electric power system. The electric power systems were researched in the following countries: Slovenia, Austria, Italy, Germany, Hungary, Czech Republic, Slovakia and Croatia.

With the purpose of valorisation of ancillary services' prices and conditions in the analysed systems, it is important to notice that there are significant differences between the analysed systems. Main geographic and demographic characteristics (depending on a country's 
population and area) already indicate the differences existing between the systems in concerned/analysed countries. Main available electric energy parameters of each EPS in any country in the world include: population size (in millions), land area $\left(\mathrm{km}^{2}\right)$, transmission system length $(\mathrm{km})$, consumption $(\mathrm{TWh}), P_{\max }(\mathrm{MW})$ and $P_{\min }$ (MW).

\subsection{Models of Procurement and Contracting of an Ancillary Service of $(f-P)$ Control with Comparison of Unit Prices in the Analysed Systems of EU/ENTSO-E}

The problem of $(f-P)$ control as an ancillary service in EPSs is important for the analysed countries and for its dynamic influence on the connected electric power system as a whole. With the purpose of an objective view of ancillary services' prices and conditions in certain systems, it is necessary to emphasise that there are significant differences between some countries.

Main geographic and demographic characteristics depending on a country's population and area already indicate the differences existing between EPSs in analysed countries. As an example, Germany with its area of 357 thousand $\mathrm{km}^{2}$ and the population of 82 million people, and Italy with its area of 301 thousand $\mathrm{km}^{2}$ and the population of 59 million people are significantly larger than Slovenia with its area of 20 thousand $\mathrm{km}^{2}$ and population of 2 million people. Some German province like Bavaria with 71 thousand $\mathrm{km}^{2}$ and population of 12.6 million people or Baden-Wurttemberg with 36 thousand $\mathrm{km}^{2}$ and population of 10.6 million people are larger than some analysed countries. Developed economies lead to very distinctive differences in electricity consumption and methods used for the system control i.e. for the ancillary services mechanism.

Table 2 The main available electric energy parameters of analysed countries in the EU [EUROSTAT 2013]

\begin{tabular}{|c|c|c|c|c|c|c|c|c|}
\hline Country & Slovenia & Austria & Italy & Germany & Hungary & Chech Republic & Slovakia & Croatia \\
\hline Population size / 000 & 2.061 & 8.507 & 60.783 & 80.767 & 9.877 & 10.512 & 5.416 & 4.248 \\
\hline Land area $/ 000 \mathrm{~km}^{2}$ & 20,3 & 83,9 & 301,2 & 357,1 & 93,0 & 78,9 & 49,0 & 56,2 \\
\hline Transmission system length / km & 2.843 & 6.977 & 63.891 & 38.000 & 4.855 & 5.503 & 2.863 & 7.513 \\
\hline Consumption / TWh & 12,2 & 69,3 & 308,4 & 543,6 & 39,5 & 62,3 & 28,2 & 17 \\
\hline$P_{\max } / \mathrm{MW}$ & 1.988 & - & 56.822 & 82.000 & 6.461 & 10.964 & 4.120 & 2.813 \\
\hline$P_{\min } / \mathrm{MW}$ & 784 & - & - & - & - & 4.700 & 2.150 & 1.105 \\
\hline
\end{tabular}

Tab. 2 presents main parameters of transmission systems in some countries. It is important to indicate that, depending on a country, the TSO may be responsible for different voltage levels. In some countries the TSO is responsible for the voltage level of $110 \mathrm{kV}$, while in some other countries the voltage level of $110 \mathrm{kV}$ is within the scope of responsibility of distribution system operators as is the case in Hungarian and German systems.

In addition to the electrical energy parameters it is important to point out the difference in the share of renewable energy sources (RES) within total electricity consumption. In Tab. 3 share of RES (Renewable Energy Sources) in gross final consumption of energy, in 2017 in the European Union (EU), reached 17,5\%, up from 17,0\% in 2016 and more than double the share in $2004(8,5 \%)$, the first year for which the data are available. The share of RES in gross final consumption of energy is one of the headline indicators of the Europe 2020 strategy. The EU's target is to obtain $20 \%$ of energy in gross final consumption of energy from RES by 2020 and at least $32 \%$ by 2030 . This is based on Eurostat data which, in line with their methodology, eliminate the impact of weather changes such as dry or wet year.

As there are significant differences between some of the analysed countries and their transmission systems, there are also differences between methods of collecting charges for ancillary services /network's usage.

The analysis showed that in Austria even $43 \%$ of the charges for network use were paid by producers, in Slovakia that was $3 \%$ paid by producers, and in other countries the same charges were paid only by electricity buyers. In Slovenia there is a separate network charge for ancillary services, primary control is not charged - it is an obligation as provided by the Grid rules while in some other countries, for example in Germany, this service presents an important market whose volume brings almost 100 million Euro annually. In light of these facts, it is not possible to make a direct comparison of deployments of some ancillary services or their unit prices between the given countries.

Table 3 The share of energy from renewable sources in analysed countries in the EU [EUROSTAT 2019] (in \% of gross final energy consumption)

\begin{tabular}{|c|c|c|c|c|c|c|c|c|c|}
\hline Country/year & Slovenia & Austria & Italy & Germany & Hungary & $\begin{array}{c}\text { Czech } \\
\text { Republic }\end{array}$ & Slovakia & Croatia & EU 28 \\
\hline 2004 & $16,1 \%$ & $22,7 \%$ & $6,3 \%$ & $6,2 \%$ & $4,4 \%$ & $6,9 \%$ & $6,4 \%$ & $23,5 \%$ & $8,5 \%$ \\
\hline 2015 & $21,0 \%$ & $32,8 \%$ & $17,5 \%$ & $14,9 \%$ & $14,4 \%$ & $15,0 \%$ & $12,9 \%$ & $29,0 \%$ & - \\
\hline 2016 & $21,3 \%$ & $33,0 \%$ & $17,4 \%$ & $14,9 \%$ & $14,3 \%$ & $14,9 \%$ & $12,0 \%$ & $28,3 \%$ & $17,0 \%$ \\
\hline 2017 & $21,5 \%$ & $32,6 \%$ & $18,3 \%$ & $15,5 \%$ & $13,3 \%$ & $14,8 \%$ & $11,5 \%$ & $27,3 \%$ & $17,5 \%$ \\
\hline 2020 target & $25 \%$ & $34 \%$ & $17 \%$ & $18 \%$ & $13 \%$ & $13 \%$ & $14 \%$ & $20 \%$ & $20 \%$ \\
\hline
\end{tabular}

\section{CONCLUSION}

This paper aims to explore the problem of technoeconomic risks related to electricity balancing of the EPS by taking into consideration an ancillary service of frequency control and active power exchange in parallel connected EPSs in the first place, along with an impact of renewable energy sources on the concerned problem.

The methodology for the risk premium calculation was presented for the need of evaluation of the market risks of electricity balancing in the EPS in terms of their manageability, and with the purpose of reducing risks and increasing safety of supply of electricity consumers. 
Application of the presented methodology was demonstrated within the paper.

There were identified and elaborated the models of a dynamic system's structure, of so called quasi-stationary static nature for the needs of providing ancillary $(f-P)$ service for the EPS balancing in a deregulated electricity market.

\section{REFERENCES}

[1] Hadzić, O. \& Bisanović, S. (2019). Risk assessment for ancillary services. International Journal of Electrical and Computer Engineering, 9(3), 1561-1568. https://doi.org/10.11591/ijece.v9i3.pp1561-1568

[2] Stoft, S. (2002). Power System Economics - Designing Markets for Electricity. Wiley-IEEE Press. https://doi.org/10.1109/9780470545584

[3] Tešnjak, S., Banovac, E., \& Kuzle, I. (2009). Electricity market (in Croatian). Graphis, Zagreb.

[4] Xai, Z. (2005). Pricing and Risk Management in Competitive Electricity Markets. PhD Theses, School of Industrial and Systems Engineering, Georgia Institute of Technology.

[5] Frunt, J. (2011).Analysis of Balancing Requirements in Future Sustainable and Reliable Power Systems. PhD Theses, Technical University of Eindhoven.

[6] ISO 31000:2009, Risk management - Principles and guidelines.

[7] Deyna, P. \& Hulstrom, M. (2007). Pricing Options on the Nordic Power Exchange Nord Pool. Stockholm.

[8] Retrieved from: http://www.investment-and-finance.net/ derivatives/e/electricity-swap-html.

[9] Pietz, M. (2009).Risikpremia in the German Electricity Futures Market, Energy and Environment. 3rd International Conference on Malacca. https://doi.org/10.1109/ICEENVIRON.2009.5398651

[10] Lucia, J. \& Torro, H. (2011). On the risk premium in Nord electricity futures prices. International Review Dynamics and Finance, 750-763. https://doi.org/10.1016/j.iref.2011.02.005

[11] Diko, P., Lawford, S., \& Limpens, V., (2006). Risk Premia in Electricity Forvard Prices. Studies in Nonlinear Dynamics \& Econometrics. https://doi.org/10.2202/1558-3708.1358

[12] HEP - OPS - Grid Code, NN 36/2006 (in Croatian).

[13] Weron, R. \& Zator, M. (2014). Revisiting the Relationship between Spot and Futures Prices in the Nord Pool Electricity Market.Energy Economics, 44, 178-190. https://doi.org/10.1016/j.eneco.2014.03.007

[14] Veraart, A. \& Veraart, L. (2013). Risk Premia in Energy Markets. CREATEC, Aarhus University. https://doi.org/10.21314/JEM.2013.102

[15] Hadžić, O. (2020).Operational balancing of the Electricity System Takoing into Account the Risks and impact of Renewable Energy Sources (in Bosnian). PhD Thesis, Faculty of Electrical Engineering, Sarajevo (in Progress).

[16] Moazeni, S., Coulon, M., Rueda, I. A., Song, B., \& Powell, W. B. (2016). A non-parametric structural hybrid modeling approach for electricity prices. Quantitative Finance, 16(2), 213-230. https://doi.org/10.1080/14697688.2015.1114363

\section{Contact information:}

Omer HADŽIĆ, MSc. Eng.

(Corresponding author)

Independent System Operator in Bosnia and Herzegovina, Board Advisor Hifzi Bjelevca 17,

71000 Sarajevo, Bosnia \& Herzegovina

E-mail: o.hadzic@nosbih.ba

Zijad BAJRAMOVIĆ, Associate Professor

University Sarajevo, Faculty of Electrical Engineering,

Electric Power Department,

Zmaja od Bosne bb, 71000 Sarajevo, Bosnia \& Herzegovina

E-mail: zbajramovic@etf.unsa.ba

\section{Sejid TEŠNJAK, Full Professor}

University of Zagreb, Faculty of Electrical Engineering and Computing,

Energy and High Voltage Department,

Unska 7, 10000 Zagreb, Croatia

E-mail: s.tesnjak@fer.hr 